\title{
METODOLOGIA PARA SIMULAÇÃO DE INJEÇÃO DE CO2 PARA ARMAZENAMENTO GEOLÓGICO EM UM REATOR DE FLUXO CONTÍNUO
}

\author{
G. F. QUANDT ${ }^{1,2}$, T. A. SIQUEIRA², R. S. IGLESIAS ${ }^{2}$, J. M. KETZER ${ }^{2}$ \\ ${ }^{1}$ Pontifícia Universidade Católica do Rio Grande do Sul, Faculdade de Engenharia Química \\ 2 Pontifícia Universidade Católica do Rio Grande do Sul, Instituto do Petróleo e dos Recursos \\ Naturais \\ E-mail para contato: gabriela.quandt@acad.pucrs.br
}

\begin{abstract}
RESUMO - A captura e o armazenamento geológico de $\mathrm{CO}_{2}$ (CCS) é uma tecnologia desenvolvida para a redução de emissões de dióxido de carbono na atmosfera. Como os meios geológicos armazenaram óleo e gás por milhares de anos, é possível supor que estes sejam estáveis para o armazenamento de $\mathrm{CO}_{2}$ também em escala de tempo geológica. A fim de melhorar a compreensão das interações geoquímicas e alterações físicas de um suposto reservatório, foi desenvolvida uma metodologia para experiências em um sistema aberto usando o reator modelo CSES-350Z $\mathrm{CO}_{2}$ Sequestration Evaluation System - CORETEST SYSTEMS, INC. em que um plugue de amostra análoga da rocha reservatório é submetido a pressão e temperatura elevadas simulando as condições de reservatório, com fluxo contínuo de $\mathrm{CO}_{2}$ puro e/ou de uma solução salina saturada com $\mathrm{CO}_{2}$. Análises de microtomografia são realizadas pré e pós-experimento, assim como análises de DR-X, MEV-EDS e Petrografia no plugue e de ICP-OES e CI nas amostras líquidas, são realizadas pós-experimento. Essas análises fornecem ferramentas para a compreensão das interações $\mathrm{CO}_{2}$-rocha-fluído a fim de verificar as alterações decorrentes dessas interações, permitindo prever o comportamento do reservatório durante o processo de EOR e estimar as melhores condições de injeção para o melhor aproveitamento da técnica.
\end{abstract}

\section{INTRODUÇÃO}

A captura e o armazenamento geológico de $\mathrm{CO}_{2}(\mathrm{CCS}$, do inglês carbon capture and storage), em reservatórios de petróleo (óleo e gás), camadas de carvão e aquíferos salinos (Figura 1) é proposta como uma das principais soluções para a redução das emissões de $\mathrm{CO}_{2}$ para a atmosfera (Ipcc, 2005; Ketzer et al. 2011). Uma vez injetado no subsolo o $\mathrm{CO}_{2}$ pode ser retido como fluído supercrítico (aprisionamento físico), a migração do fluído pode ocorrer muito lentamente em um aquífero (aprisionamento hidrodinâmico), o $\mathrm{CO}_{2}$ pode ser dissolvido em águas subterrâneas (aprisionamento por solubilização), e pode também ocorrer o aprisionamento mineral, na forma de carbonatos precipitados (Gunter et al., 1993; Gunter et al., 2000). 
Figura 1. Visão geral das opções de armazenamento geológico (Ipcc, 2005; Ketzer et al., 2011).

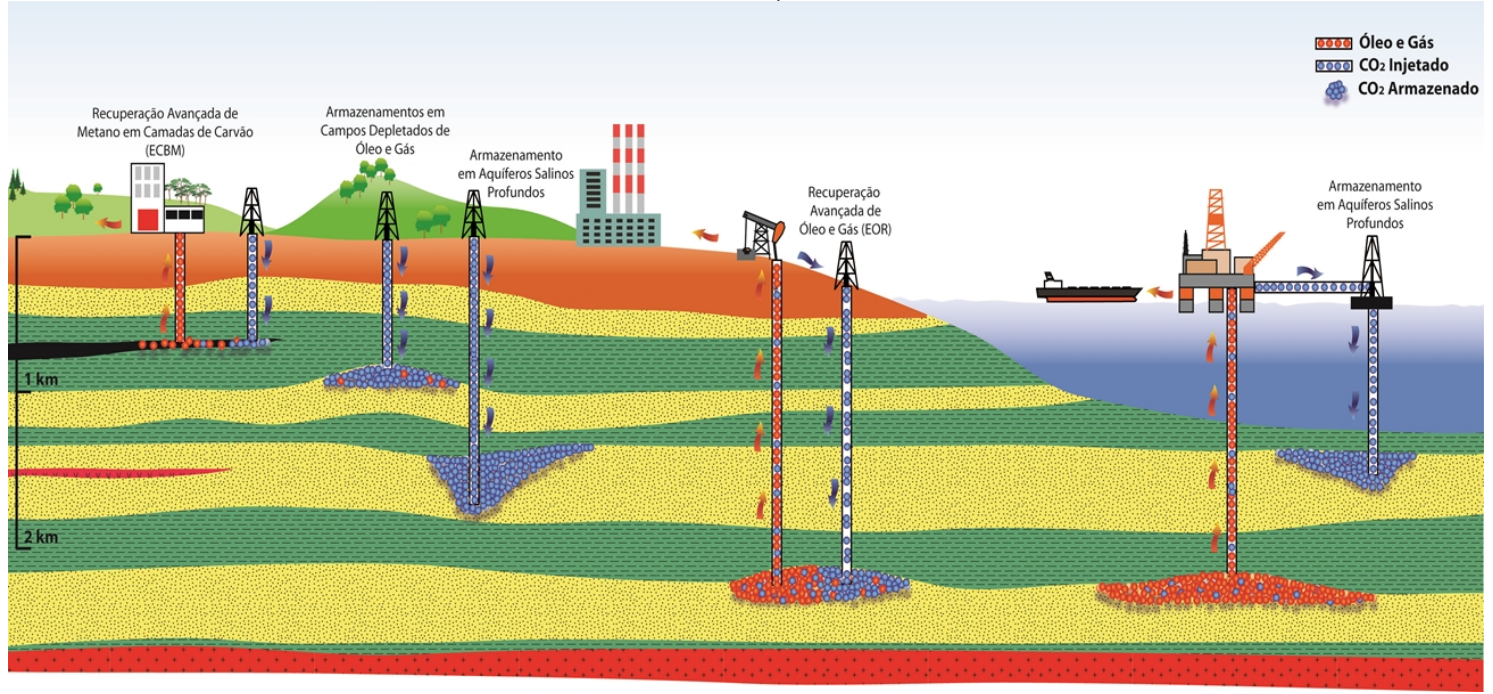

CCS é uma tecnologia desenvolvida para a redução de emissões de dióxido de carbono na atmosfera. Como os meios geológicos armazenaram óleo e gás por milhares de anos, é possível supor que estes sejam estáveis para o armazenamento de $\mathrm{CO}_{2}$ também em escala de tempo geológica. A injeção de $\mathrm{CO}_{2}$ em reservatórios de petróleo não é interessante apenas do ponto de vista ambiental, mas também pelo aspecto econômico: quantidades adicionais de óleo e gás podem ser recuperadas em um campo através deste processo (denominado recuperação avançada, ou simplesmente EOR, do inglês enhanced oil recovery). Esta técnica permite uma recuperação de até $45 \%$ da quantidade original de hidrocarbonetos no reservatório.

As possíveis reações químicas induzidas pela injeção de $\mathrm{CO}_{2}$ durante o processo de EOR são descritas por Ortoleva et al. (1998). Inicialmente, a dissolução e $\mathrm{CO}_{2}$ em meio aquoso provoca uma acidificação significativa do meio, pela formação de ácido carbônico:

$$
\mathrm{CO}_{2 \text { (aq.) }}+\mathrm{H}_{2} \mathrm{O} \leftrightarrow \mathrm{H}_{2} \mathrm{CO}_{3}
$$

Este ácido se dissocia gerando íons bicarbonato:

$$
\mathrm{H}_{2} \mathrm{CO}_{3}+\mathrm{H}_{2} \mathrm{O} \leftrightarrow \mathrm{H}_{3} \mathrm{O}^{+}+\mathrm{HCO}_{3}^{-}
$$

Em presença de cátions de metais alcalino-terrosos $\left(\mathrm{Ca}^{2+}, \mathrm{Mg}^{2+}\right.$, etc. $)$ ou metais divalentes $\left(\mathrm{Fe}^{2+}, \mathrm{Mn}^{2+}\right)$, ocorrerá complexação com o bicarbonato:

$$
\mathrm{Ca}^{2+}+\mathrm{HCO}_{3}^{-} \longleftrightarrow \mathrm{Ca}\left(\mathrm{HCO}_{3}\right)_{2}
$$

Em pH adequado (neutro a alcalino, normalmente acima de 7), ocorrerá precipitação de carbonatos, imobilizando o carbono em uma forma sólida (Gunter et al., 1997):

$$
\mathrm{HCO}_{3}{ }^{-}+\mathrm{Ca}^{2+}+\mathrm{H}_{2} \mathrm{O} \longleftrightarrow \mathrm{CaCO}_{3(\mathrm{~s})}+\mathrm{H}_{3} \mathrm{O}^{+}
$$


Os cátions divalentes podem ter origem no próprio fluído presente no reservatório, ou na dissolução de minerais da formação (silicatos de cálcio, ferro e/ou magnésio), provocada pela injeção do $\mathrm{CO}_{2}$. A extensão do armazenamento mineral estará diretamente relacionada à quantidade disponível destes cátions em solução.

Em escala laboratorial é possível realizar experimentos que visam simular as condições de reservatório, bem como os efeitos da injeção do gás carbônico, podendo facilitar a previsão de possíveis falhas, já que a interação geoquímica entre os fluidos do reservatório e novos fluidos durante o processo de produção, juntamente com os minerais presentes no reservatório pode causar alterações nas propriedades do mesmo (porosidade e permeabilidade, por exemplo).

Esses experimentos podem ser realizados através de dois métodos: em reatores batelada ou de fluxo contínuo. Os experimentos em fluxo contínuo resultam em uma simulação mais realista das pressões exercidas em um reservatório geológico.

\section{METODOLOGIA}

A fim de melhorar a compreensão das interações geoquímicas e alterações físicas de um suposto reservatório, o Laboratório de Modelagem Geoquímica desenvolveu uma metodologia para experiências em um sistema aberto usando o reator modelo CSES-350Z $\mathrm{CO}_{2}$ Sequestration Evaluation System - CORETEST SYSTEMS, INC. disponível no IPR (Figura 2), em que um plugue de amostra análoga da rocha reservatório é colocado em uma célula de Hassler, e submetido a uma pressão elevada simulando as condições de reservatório, com fluxo contínuo de $\mathrm{CO}_{2}$ puro e/ou de uma solução salina saturada com $\mathrm{CO}_{2}$.

Figura 2. Representação esquemática do equipamento usado em experimentos de interações $\mathrm{CO}_{2}$-rocha-fluído no IPR.

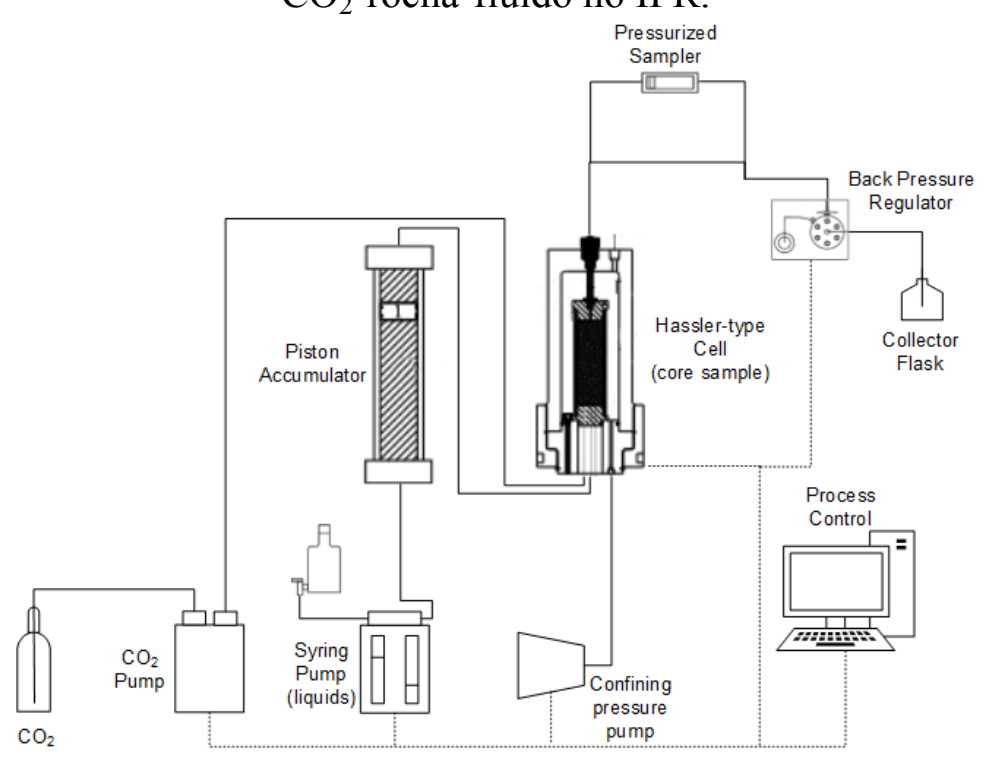

\subsection{Confecção do Plugue e Preparação da Amostra}


Para a confecção do plugue é necessária uma amostra análoga de rocha que será perfurada por uma broca e resultará em um corte de formato cilíndrico, que pode ter um comprimento variável de 2.5 a 8.0 polegadas e um diâmetro fixado de 1.0 ou 1.5 polegadas. Essas medidas são as especificações do equipamento.

Antes da realização do experimento são necessários alguns passos para preparar a amostra, um deles é submetê-la à microtomografia, que será realizada pré e pós experimento para comparação e identificação de "novos caminhos" dentro da rocha ou de possíveis fraturas.

Após a microtomografia, a amostra é colocada em contato com uma solução salina sintética, para saturação por um período de $24 \mathrm{~h}$ para que seja estabelecido um equilíbrio parcial entre a rocha e a solução salina. A solução representa a água de formação presente dentro do reservatório, e irá exercer a pressão de poro, que nada mais é do que a pressão de um fluido dentro dos poros da rocha.

Após o período de saturação a amostra é preparada através do envolvimento do plugue em uma camisa de teflon termo retrátil (Figura 3a) e, posteriormente em uma camisa de viton de parede grossa (Figura 3b) presa por braçadeiras metálicas. Após o encapsulamento, a amostra é inserida no núcleo do reator.

Figura 3. a) Plugue envolvido em uma camisa de teflon termo retrátil, b) Plugue envolvido por uma camisa de teflon termo retrátil e por uma camisa de viton.

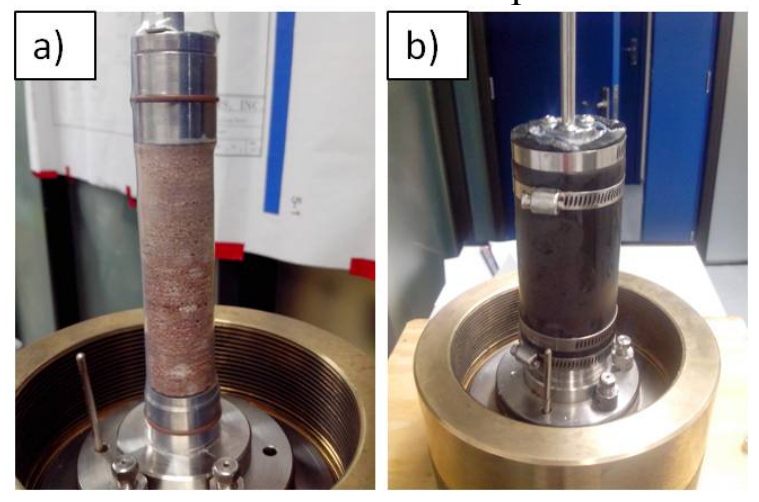

As soluções salinas sintéticas são preparadas no dia do início do experimento e são caracterizadas pré e pós-reação através de análises de cátions (ICP-OES) e ânions (CI cromatografia iônica), sendo suas composições definidas a partir de dados composicionais das águas de formação dos reservatórios de interesse.

\subsection{Aplicação da Pressão e Amostragem}

A solução salina é carregada no início do experimento em um reservatório acumulador acionado por um pistão hidráulico através de uma bomba do tipo QUIZIX QX Pump.

Após o preparo da amostra e sua inserção no núcleo do reator é aplicada a pressão de confinamento podendo atingir até 9900 PSI de pressão hidrostática, que é aplicada através de sistema de confinamento independente. A pressão de confinamento é mantida por aproximadamente $2 \mathrm{~h}$ para estabilizar sendo nesse período ligada a estufa de aquecimento 
para estabilizar a temperatura desejada. Ao estabilizar a pressão de confinamento e a temperatura do núcleo é iniciado o processo de injeção de $\mathrm{CO}_{2}$.

A injeção de $\mathrm{CO}_{2}$ em estado supercrítico e solução salina ocorre com o auxílio de uma bomba de pressurização de $\mathrm{CO}_{2}$ e da QUIZIX pump, que podem pressurizar o sistema até 6600 PSI de pressão de poro e um fluxo máximo de $50 \mathrm{~mL} / \mathrm{min}$. Podem ser realizadas amostragens de fluídos através de um amostrador de titânio para altas pressões e alta salinidade, bem como amostragens a condições ambientes sem interromper a reação. As reações podem ser realizadas em temperaturas de até $150{ }^{\circ} \mathrm{C}$.

\section{Resultados Esperados}

Após os experimentos são analisadas as amostragens por meio de análise de ICP-OES e CI. O plugue da rocha utilizado na reação pode ser analisado por microtomografia, e deverá passar também por análises de DR-X, MEV-EDS e Petrografia a fim de verificar as modificações ocorridas durante o processo.

Essas análises fornecem ferramentas para a compreensão das interações $\mathrm{CO}_{2}$-rochafluído a fim de verificar as alterações decorrentes dessas interações, permitindo prever o comportamento do reservatório durante o processo de EOR e estimar as melhores condições de injeção para o melhor aproveitamento da técnica.

\section{REFERÊNCIAS}

GUNTER, W.D.; PERKINS, E.H.; McCANN, T.J. Aquifer disposal of CO2-rich gases: reaction design for added capacity. Energy Conversion and Management, V. 34, 941-948, 1993.

GUNTER, W.D., PERKINS, E.H., HUTCHEON, I. Aquifer disposal of acid gases: modelling of water-rock reactions for trapping of acid wastes. Appl. Geochem. V. 15, 1085-1095, 2000

IPCC. Special Report on Carbon Dioxide Capture and Storage. Intergovernmental Panel on Climate Change. New York, USA, p.431. 2005

KETZER, J. M.; IGLESIAS, R. S.; EINLOFT, S. Reducing Greenhouse Gas Emissions with $\mathrm{CO}_{2}$ Capture and Geological Storage. In: WEI-YIN CHEN, J. S., TOSHIO SUZUKI \& MAXIMILIAN LACKNER (Ed.). Handbook of Climate Change Mitigation: Springer Science+Business Media, LLC, 2011.

ORTOLEVA, P. J.; DOVE, P.; RICHTER, F. Geochemical perspectives on $\mathrm{CO}_{2}$ sequestration., U.S Department of Energy Workshop "Terrestrial Sequestration of CO2 - An Assessment of Research Needs", 1998, Gaithersburg, MD. 